\title{
Reseña
}

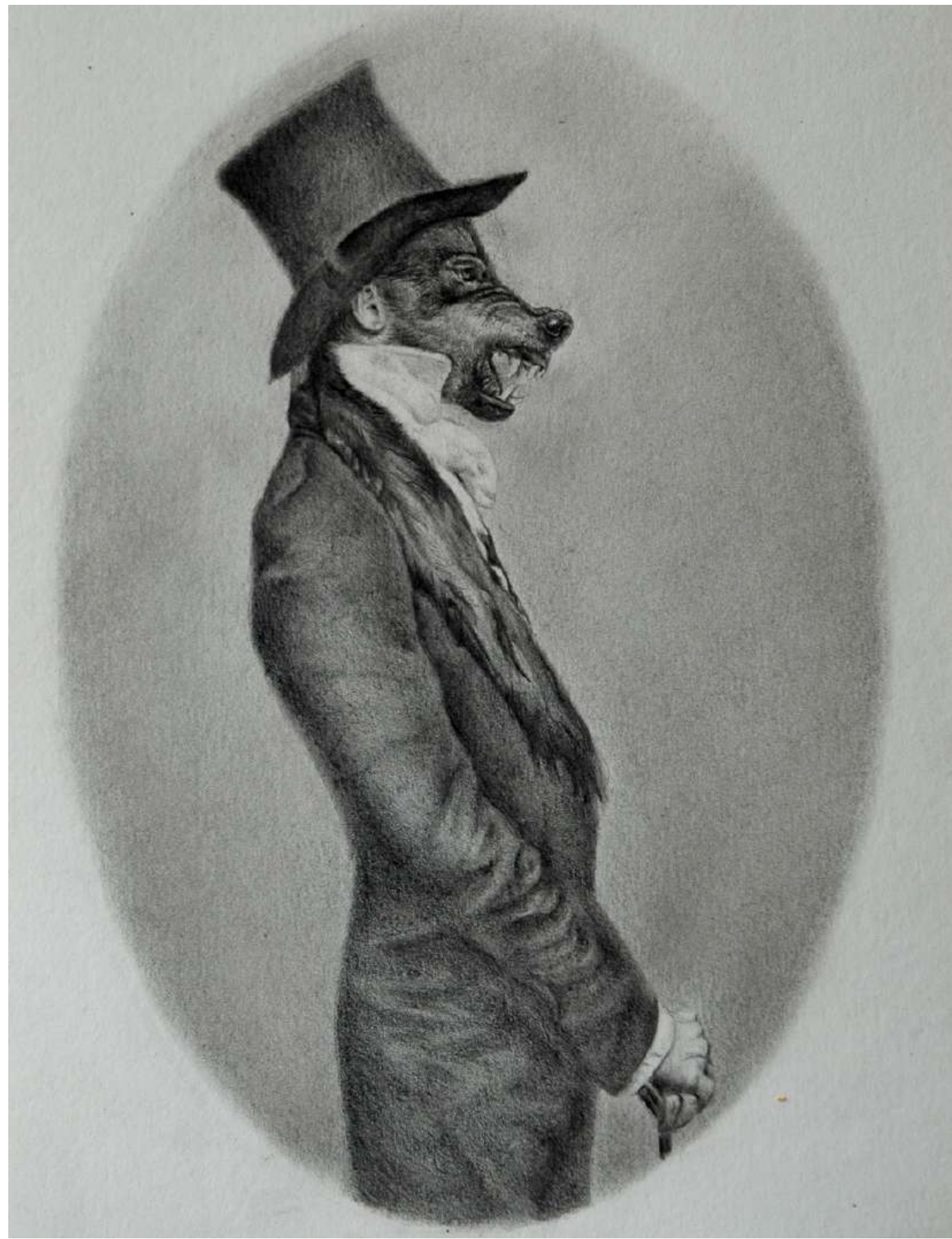

Sin título

De la serie Un viaje hacía el origen

Grafito sobre papel

$20 \times 10 \mathrm{~cm}$

2019

Medellín 


\section{García, Pío. (2018). Globalización y regiones. El diálogo Asia-América Latina y el Caribe. Bogotá, D. C: Universidad Externado de Colombia. ${ }^{*}$}

Este libro explora las posibilidades de la integración birregional entre Asia, América Latina y el Caribe como estrategia de enriquecimiento y diversificación de los relacionamientos de los países que conforman estas dos regiones y, de paso, para el enriquecimiento y dinamización de la estructura política mundial. La hipótesis central plantea que las dinámicas intrarregionales y los desafíos globales, junto con la experiencia de encuentro y concertación, ofrecen nuevas condiciones favorables al examen e implementación de un programa de cooperación interregional recio, amplio y de largo alcance entre Asia y América Latina y el Caribe, del que depende el bienestar de sus pueblos y su integración social, así como el arraigo del cosmopolitismo y la gobernanza global (pp. 30-31).

El autor combina un recorrido histórico por las relaciones históricas de estas dos regiones con un análisis sobre las potencialidades que tendría una agenda programática birregional más consolidada entre Asia y América Latina y el Caribe. Esta lectura incorpora elementos prescriptivos inspirados en los fundamentos axiológicos del institucionalismo multilateral, ya que se entiende este encuentro birregional como una significativa posibilidad para que la región latinocaribeamericana expanda sus relaciones con otras culturas y mercados, ampliando sus intercambios con el mundo, más allá de la tradicional senda de relaciones políticas y económicas con Estados Unidos y Europa occidental.

Estas ideas se desarrollan en ocho capítulos. Los dos primeros tienen como objetivo explorar los fundamentos de la integración regional, así como hacer un balance de los procesos de concertación e integración que se han configurado en términos interregionales entre Asia y América Latina y el Caribe. En los siguientes cinco capítulos el autor examina las relaciones de cinco países de la región asiática —China, India, Rusia, Japón y Coreacon América Latina y el Caribe, en los que se hace un balance de los nexos que han tenido lugar históricamente, los factores favorables y desfavorables

* http://doi.org/10.17533/udea.espo.n55a13 
que han permitido o restringido sus relacionamientos, y una prospectiva hacia la consolidación de agendas económicas, políticas, estratégicas y culturales entre esos países de la región asiática con los países de América Latina y el Caribe.

En el último capítulo se ofrece un prospecto de la cooperación entre estas dos regiones.

El libro comienza haciendo una revisión de los fundamentos económicos, estratégicos y político-culturales de la integración regional que se encuentran en diversos enfoques teóricos, como el funcionalismo, el neorrealismo, el sistémico, el construccionista y la teoría crítica. Cada una de estas perspectivas ofrece argumentos explicativos y normativos sobre cuáles son los fundamentos de índole económico, político, cultural, geopolítico y estratégico que se han esgrimido para justificar la integración birregional. Por supuesto, los diagnósticos son muy diferentes dependiendo de cada perspectiva. Teniendo presente ese trasfondo teórico, el autor expone los fundamentos que a su modo de ver justifican la integración birregional desde el sistema de valores y principios del institucionalismo multilateral.

[316] Por otra parte, en cuanto al balance que hace sobre la concertación y la integración histórica entre estas dos regiones, se plantea como hipótesis que «los procesos de integración en Asia y América Latina y el Caribe marchan a distinta velocidad y en arreglos institucionales contrastantes, que ponen en evidencia estrategias dispares de concertación» (p. 64). Esto se corrobora a lo largo del libro, al evidenciar ambas experiencias de cooperación intrarregional e interregional, en las cuales el balance es más favorable para los procesos de integración intrarregional asiática, mucho más fuertes y consolidados institucionalmente, aunque también con dificultades, frente a los procesos débiles e inconstantes de los países de América Latina y el Caribe, los cuales también tienen impactos en las condiciones desiguales en las que se podrían trazar nuevas agendas.

Aun así, se plantea que este factor no puede ser razón suficiente para dejar de proyectar escenarios de cooperación entre ambas partes. Coherente con esta posición, el autor identifica varios asuntos que deberían incorporarse en una agenda de cooperación birregional Asia-América Latina y el Caribe. Entre ellos, propone que el desarrollo económico y social sostenible constituya un eje articulador de esa cooperación, encarrilada a través de la figura Asia-Celac Meeting (ACEM). 
El abordaje histórico de las relaciones entre China, Rusia, India, Japón y Corea con los países de Latinoamérica y el Caribe presenta un panorama muy diverso en relación con los factores económico, político, social y cultural que han motivado estos relacionamientos, los países concretos con los cuales han sostenido relaciones, los mecanismos institucionales a través de los cuales se han formalizado esos nexos, los factores que potenciarían el fortalecimiento de políticas de interacción entre países de ambas regiones, así como los que habría que remover para lograr agendas colaborativas.

Frente a las relaciones con China, el autor plantea que estas revigorizan el sistema mundial multilateral y aportan a la generación de un equilibrio global. A pesar de los mitos racistas occidentales que por mucho tiempo fueron difundidos sobre China, este país ha consolidado su poder blando en América Latina y el Caribe, así como su influencia económica en la región, a través de importantes inversiones en diversos sectores de la economía. Pero no todo ha sido relaciones económicas. China también ha fortalecido sus relaciones políticas, con claros principios de no intervención, no injerencia, coexistencia pacífica y beneficios mutuos, dentro de arreglos institucionales multilaterales. Esta forma de proceder le ha permitido manejar un bajo perfil político en la región, más pragmático que ideológico, frente al ojo vigilante y receloso de Estados Unidos. Este balance también muestra que han prevalecido las relaciones de China con Brasil, Venezuela, México y Argentina como socios estratégicos, y con Chile, Perú y Cuba como socios en materia de cooperación. Finalmente, el autor plantea que los relacionamientos con China también pueden traer desventajas para los países latinoamericanos y del Caribe. Señala que aún deben examinarse con detenimiento los costos de las inversiones económicas que realiza China en la región, particularmente en cuanto a los medioambientales.

El análisis de las relaciones entre India y América Latina y el Caribe evidencia un intercambio mucho menor del que se presenta con China. Algunas de las causas que se han identificado para explicar esta poca interacción se fundamentan en la distancia física y cultural, el impacto de la geopolítica, factores domésticos y, principalmente, el hecho de ser un país que, por su industria manufacturera, resulta ser competidor de países latinocaribeamericanos en varios mercados. Aun así, el autor plantea que resulta conveniente establecer de agendas de cooperación en temas como el medio ambiente, el bienestar colectivo, la medicina, el desarrollo empresarial y las relaciones culturales. 
El balance con Rusia evidencia un contraste en las relaciones antes y después de la desintegración de la Unión Soviética. Las relaciones estuvieron mediadas por factores ideológicos durante la Guerra Fría y, posteriormente, con relaciones menos políticas y más vinculadas al intercambio económico. Según el autor, las interacciones entre Rusia y América Latina y el Caribe han estado limitadas por el tutelaje de Estados Unidos en la región, lo cual ha sido un factor inhibidor del desarrollo más amplio de esas relaciones. Los datos de intercambio comercial evidencian que Latinoamérica no es una región prioritaria en el desarrollo económico de Rusia, ya que sus mayores nexos económicos están en Asia-Pacífico y en Europa. En ese sentido, el autor identifica que la influencia de Rusia en la región ha sido recurrentemente sobredimensionada y los datos han sido frecuentemente inflados. Adicionalmente, señala que la prioridad de Rusia de desarrollar su economía a través de la industria energética, así como el bajo desarrollo institucional de la política exterior en los países latinocaribeamericanos, son dos factores que también juegan en contra de lograr mayores articulaciones. Sin embargo, identifica varios campos en los cuales pueden establecerse agendas conjuntas, por ejemplo, en términos de integración económica, cualificación profesional, desarrollo de alianzas y cooperación en el cumplimiento de los objetivos del milenio, el desarrollo de los derechos humanos y la internacionalización.

En el plano de las relaciones entre América Latina y el Caribe y Japón, se plantea que este último ha sido el país con el cual se han sostenido mayores puentes con Asia, gracias a muchos años de relaciones comerciales, cooperación técnica y la inversión en programas educativos. Se reconoce que la migración laboral de japoneses hacia el continente americano durante la primera mitad del siglo xx fue el primer factor que alentó relacionamientos en términos de intercambio económico y cultural, ya que estos viajaban con sus familias y formaron colonias en los países latinocaribeamericanos donde se asentaron. Posterior al proceso de industrialización de Japón en la década de 1970, las relaciones han trascendido al plano de lo comercial, el desarrollo tecnológico y las inversiones económicas. Sin embargo, el autor resalta que la agenda de intercambio con Japón no debe limitarse al plano económico, ya que existen otros escenarios en los cuales puede ser muy provechoso el cultivo de relaciones de cooperación. De manera central se resalta la posibilidad de generar agendas conjuntas de trabajo en torno a la seguridad humana. 
Finalmente, el libro explora las proyecciones de Corea del Sur en América Latina y el Caribe. El análisis de las relaciones con este país se focaliza en examinar la influencia que ha tenido el desarrollo de relaciones económicas a través de la figura de acuerdos comerciales preferenciales, especialmente a través de tratados de libre comercio, como el firmado con Chile en 2003, Perú en 2011 y Colombia en 2013. Este capítulo concluye que las relaciones con Corea del Sur han estado mediadas por el factor comercial a través de los tratados de libre comercio, que en casos como el colombiano se ha tratado de relaciones modestas y que han generado tensiones domésticas por las condiciones desfavorables de Colombia para establecer relaciones bajo la figura de acuerdos comerciales preferenciales con un país que cuenta con un mayor desarrollo tecnológico e industrial.

El libro concluye abordando el tema de las bases institucionales, valorativas, las formas de cooperación, los mecanismos de integración y las agendas programáticas que deberían reorientar las relaciones birregionales entre Asia y América Latina y el Caribe. En cuanto a las bases normativas, el autor manifiesta una explícita posición a favor de que sean los arreglos institucionales multilaterales los que inspiren y orienten la cooperación interregional. En cuanto a la base institucional que coordine las relaciones de cooperación, se plantea la posibilidad de emplear plataformas organizativas de ambas regiones, como la Asociación Económica Regional Amplia (RCEP), la Organización de Cooperación de Shangai (OCS) y la Comunidad de Estados Latinoamericanos y Caribeños (Celac). Otra posibilidad que se manifiesta es la articulación vía ACEM. Finalmente, propone que esta agenda se consolide bajo un enfoque sistémico que se articule mediante catorce subsistemas sociales: parentesco, salud, manutención, lealtad, recreación, comunicación y transporte, pedagógico, patrimonial, producción, religión, seguridad, política, administración, jurídica y precedencia.

Como se esgrimió al comienzo de la reseña, este libro constituye un aporte al estudio, reflexión y exploración de nuevas oportunidades de relacionamiento económico, político y sociocultural para los países latinoamericanos y caribeños, que tienen tanto para ofrecer y tanto por aprender. Todo esto en el marco de nuevas agendas políticas intrarregionales e interregionales que atiendan a las nuevas dinámicas de interdependencia mundial, que apunten hacia la consolidación de una gobernanza mundial democrática, horizontal, interdependiente y abierta a desarrollar mecanismos 
de cooperación y coordinación colaborativa, basada en el diálogo, en el cosmopolitismo y la interculturalidad, en el respeto por la soberanía de los pueblos, superando las tradicionales y obsoletas formas de relacionamiento basadas en el control, la injerencia y las nuevas formas de colonización que hacen a unos pueblos dominantes y a otros dominados.

Jonathan Alejandro Murcia (Colombia) ${ }^{1}$

${ }^{1}$ Politólogo. Magíster en Derecho. Facultad de Derecho y Ciencias Políticas, Universidad de Antioquia UdeA. Calle 70 No.52-21, Medellín, Colombia. Correo electrónico: jonathan.murcia@udea.edu.co 